\title{
Semantic relations between encoding and retrieval in cued recall
}

\author{
LORRAINE A. LOW \\ Framingham State College, Framingham, Massachusetts \\ and \\ BEVERLY J. RODER \\ Tufts University, Medford, Massachusetts
}

\begin{abstract}
Two experiments were conducted to test the encoding-specificity hypothesis. In Experiment 1 , subjects were presented pairs of coordinates to study, followed by a cued-recall test. Semantically weak and strong coordinates (defined by the degree of featural overlap shared with the pairs) served as encoding and retrieval cues. The semantic strength of the retrieval cue proved to be the most important factor in recall, whereas the re-presentation of an unrelated cue previously seen during encoding led to no facilitation of recall. In Experiment 2, three noun coordinates of varied semantic interrelatedness were presented for study and then were cued for recall by novel semantically strong or weak coordinates. Maximum recall was achieved when a strong encoding condition was matched with a strong retrieval cue. Implications of these findings for an encoding-specificity hypothesis were discussed.
\end{abstract}

A major concern of memory theorists is the representation in memory of verbal material. Semantic theories of memory hold that tasks that involve word recall require that a connection be made between the to-be-remembered word and its previous associations. A good deal of experimental evidence suggests that this semantic component of the memory process is characterized by an automatic arousal of those concepts that are related to the word (Conrad, 1974; Warren \& Warren, 1976; Yates, 1978).

The encoding-specificity principle advanced by Tulving and his associates (Thomson \& Tulving, 1970; Tulving, 1979; Tulving \& Osler, 1968; Tulving \& Thomson, 1973) offers an alternative approach to the representation of words in memory. According to this principle, items are encoded as they occur within a particular context, and retrieval is contingent upon reinstatement of the original encoding conditions (the "episodic context"). As explained by Tulving and Thomson (1973), "Specific encoding operations performed on what is perceived determine what retrieval cues are effective in providing access to what is stored" (p. 369). Tulving (1979) further stated: "The compatibility relation between the trace and the cue, as a necessary condition of recollection of an event, is determined by specific encoding operations at the time of study and not by the properties of cues and target items, and their relations, in semantic memory" (p. 408).

Both authors contributed equally to the study. The authors are listed in alphabetical order. Requests for reprints should be sent to Lorraine A. Low, Department of Psychology, Framingham State College, Framingham, Massachusetts 01701.
The encoding-specificity hypothesis has been interpreted variously. A strict interpretation of the principle would imply that if there is a lack of compatibility between the episodic context and the semantic context, the former, but not the latter, would provide the basis for retrieval. Tulving and his associates claimed to have provided empirical support for such an interpretation in a series of studies (Thomson \& Tulving, 1970; Tulving \& Olser, 1968; Tulving \& Thomson, 1973).

However, a theory of verbal recall that favor, episodic factors over semantic factors runs counter :u much experimental evidence. The importance of maintaining the compatibility of the semantic relations formed during encoding with that aroused during retrieval has been established in numerous studies measuring both recognition (Light \& Carter-Sobell, 1970) and recall (Murphy \& Wallace, 1974; Pellegrino \& Salzberg, 1975; Roediger \& Adelson, 1980; Thomson \& Tulving, 1970).

The point has been made, however, that a theory of encoding specificity is not necessarily inconsistent with a semantic interpretation of processing. A number of investigators (Martin, 1975; Reder, Anderson, \& Bjork, 1974; Roediger \& Adelson, 1980; Santa \& Lamwers, 1974) have advanced the argument that the pairing of two words results in the arousal of a very specific contextual meaning that necessarily alters the hierarchy of the strength of association of other words to the pair. For example, Tulving and Thomson's (1973) study paired the target COLD with a supposedly weak associate, GROUND, during encoding. In subsequent cued recall, GROUND was found to be a stronger retrieval cue for COLD than was a previously unseen strong associate of the target, HOT. Tulving and Thomson 
argued that this demonstrated the importance of reinstituting the episodic conditions present at encoding to evoke recall. A semantic interpretation would argue that the very linking of the two words (COLD/GROUND) produced a contextual meaning that greatly accentuated particular features of each word and diminished others. What resulted was a very specific semantic trace to which HOT, a strong associate of COLD in its isolated context, became a poor associate for COLD when COLD was presented as part of the COLD/GROUND pair.

Numerous theorists (Reder, Anderson, \& Bjork, 1974; Roediger \& Adelson, 1980), including Tulving (Flexser \& Tulving, 1978), in a modification of his original position, have attempted to include within the notion of encoding specificity, the semantic "sense" (interpretation) of the encoded unit as an important component of the episodic context. Roediger and Adelson, for example, described the likelihood of recall in terms of the informational overlap between the encoding and retrieval environments. This "episodic" information presumably includes semantically contextual biases as well as such strictly perceptual cues as orthography, other words accompanying the target, etc.

We agree that an interpretation of encoding specificity that emphasizes semantic factors provides a more plausible explanation of the processes underlying word recall than does a strictly episodic interpretation. The question remaining is whether even this attenuated version of the principle is useful. Even the most liberal interpretation of encoding specificity would imply that, however small or great the contribution, all episodic factors attended to influence (to some extent) the character of the trace.

In an initial attempt to illuminate this issue, we conducted a pilot study in our laboratory in which we pitted semantic factors against strictly episodic factors. To avoid the confound discussed above (that of creating a contextual bias by pairing single targets with encoding cues), we defined semantic context independently of the encoding cues. This was accomplished by using, as our targets, noun pairs that were category coordinates of a common superordinate category. Appropriate and inappropriate superordinate category names served as encoding and retrieval cues. Four experimental conditions were thus produced: (1) No encoding cue/appropriate retrieval cue (N/A) (e.g., DAISY/LILY, studied in the absence of an encoding cue and cued for retrieval by FLOWER); (2) appropriate encoding cue/appropriate retrieval cue (A/A) (e.g., BEAR/LION, studied with the encoding cue ANIMAL and cued for retrieval with ANIMAL); (3) inappropriate encoding cue/appropriate retrieval cue (I/A) (e.g., HAMMER/SAW, studied with CLOTHES and later cued by TOOL); and (4) inappropriate encoding cue/inappropriate retrieval cue (I/I) (e.g., TRACTOR/PLOW, studied with FABRIC and cued for retrieval with FABRIC).

We found significant differences (alpha $\leqslant .01$ ) between all conditions, with $\mathrm{A} / \mathrm{A}$ words being recalled best, followed by N/A, I/A and finally I/I words. Thus, in comparison with targets presented without an encoding cue, the reappearance of a previously seen appropriate cue at retrieval ( $\mathrm{A} / \mathrm{A}$ condition) clearly augmented recall; conversely, the reappearance of a previously seen inappropriate cue ( $\mathrm{I} / \mathrm{I}$ condition) resulted in an impairment.

The poor performance in the I/I condition posed problems for the episodic hypothesis, since in that condition perceptual invariance was maintained between encoding and retrieval. This might have been interpreted as a strong argument against the notion of encoding specificity had it not been for the total lack of any semantic congruity between the targets and the encoding cue in this condition. In other words, there was the possibility that the apparent irrelevance of the encoding cue to the targets may have resulted in its being entirely ignored during encoding. Experiment 1 was designed to rule out this possibility.

\section{EXPERIMENT 1}

The purpose of Experiment 1 was to compare perceptual and semantic invariance of encoding and recall cues under conditions in which semantic compatibility was established between these cues and target items in all conditions. As in the pilot study, we established a semantic context by purposely selecting two coordinates that shared a strong featural similarity to serve as our targets. (For example, ROBIN and SPARROW would be considered to share a great many common features; ROBIN and TURKEY would not.) All cues were also coordinates of the targets, uniquely encoded for their particular target pairs and semantically compatible with them. Encoding and retrieval cues were defined as "weak" or "strong" on the basis of the degree of featural overlap shared with the targets. Strong cues shared a greater number of features with the target pair than did weak cues; nevertheless, weak cues shared a sufficient number of features with the targets to meet Moscovitch and Craik's (1976) criteria as adequate retrieval cues. Thus, we were able to vary independently the strength of the encoding and retrieval cues. In addition, functional equivalence in cue strength could be achieved while the perceptual similarity between encoding and retrieval was varied. Experiment 1 was, therefore, designed to assess independently the contribution of semantic and perceptual similarity in features between encoding and retrieval in cued recall.

\section{Method}

Subjects. Forty students (20 males and 20 females) were recruited from the Framingham State College population. Participation was voluntary. Equal numbers of males and females were assigned randomly to Lists 1 and 2 and were individually tested.

Materials and Procedure. Four nouns that shared a high degree of featural similarity and were coordinate members of the same category were selected from each of 24 categories. The 
stimulus words that were used in Experiment 1 appear in Appen$\operatorname{dix}$ A. Two nouns from each of these four-noun groups were chosen randomly to serve as the target pair; the remaining two nouns were designated as "strong" cues and were used as encoding and retrieval cues for the target pair. Two additional category members were then generated for each category to serve as "weak" encoding and retrieval cues. These latter nouns were chosen on the basis of their minimal featural similarity to the four previously selected nouns as well as their minimal featural similarity to one another. For example, for the category FABRIC, SATIN and SILK represented a target pair, TAFFETA and VELVET were "strong" encoding and/or retrieval cues, and DENIM and CANVAS were "weak" cues. Designation of nouns as encoding or retrieval cues was determined randomly within the confines of the weak/strong distinction except in those cases in which cross-cuing might have resulted.

Two lists were constructed; however, due to the need to avoid overlapping categories in this experiment, we were able to generate only 24 test categories. Therefore, the same 24 categories were represented on each study list. Items that were cued by strong retrieval cues in List 1 were presented in weak-retrievalcue conditions in List 2.

A $2 \times 8$ mixed design was employed, with list as a betweengroups factor and cue condition as a within-group factor. The eight cuing conditions were: (1) no encoding cue/strong retrieval cue $(\mathrm{N} / \mathrm{S})$-target pairs studied in the absence of any encoding cue and recalled with a strong retrieval cue (e.g., OAK/MAPLE, studied without an encoding cue and cued for recall with ELM); (2) strong encoding cue/identical retrieval cue (S/IS)-target pairs studied in the presence of a strong encoding cue that later reappeared as the retrieval cue (e.g., SATIN/SILK, studied with TAFFETA and retrieved with TAFFETA); (3) weak encoding cue/strong retrieval cue (W/S)-target pairs presented with a weak encoding cue, but later cued for recall with a strong retrieval cue (e.g., LEOPARD/JAGUAR, studied with DINOSAUR and later retrieved with TIGER); (4) strong encoding cue/different strong retrieval cue (S/DS)-target pairs studied in the presence of a strong encoding cue and cued for recall with a novel strong cue (e.g., BEER/RUM, studied with WHISKEY and later retrieved with WINE); (5) no encoding cue/weak retrieval cue $(N / W)$-target pairs studied in the absence of an encoding cue and cued at recall with a weak retrieval cue (e.g., ROBIN/SPARROW, studied without an encoding cue and later cued for recall with TURKEY); (6) weak encoding cue/ identical weak retrieval cue (W/IW)-target pairs presented with a weak encoding cue that later reappeared as the retrieval cue (e.g., SOX/SLIPPERS, studied with BELT and later retrieved with BELT); (7) strong encoding cue/weak retrieval cue (S/W)target pairs studied with a strong encoding cue and recalled with a weak retrieval cue (e.g., EYE/NOSE, studied with EAR and retrieved with KNEE); and (8) weak encoding cue/different weak retrieval cue (W/DW)-target pairs studied accompanied by a weak encoding cue and then cued at recall with a different weak cue (e.g., ASSAULT/MURDER, studied with PLAGIARISM and retrieved with JAYWALKING).

The order of item presentation was randomized separately for each list within blocks of eight, guaranteeing that one representative of each cuing condition appeared within each eightstimulus block. Retrieval cues were randomized similarly, with the restriction that cues corresponding to the last six items on the study list did not appear among the first six recall cues.

The subjects were given stimulus cards and were told that a pair of nouns would be printed on each card and that an additional third word would appear below the pair on some. The subjects were instructed to try to remember the noun pairs for a subsequent recall test. It was suggested that they use the third words, whenever present, to help them to remember.

The subjects were told to study each card for $5 \mathrm{sec}$ and then, on hearing the instruction "Turn," to turn over the top card and go on to study the words on the next card. The top card of the stack was marked with the list number; the last card in the series was marked "END." Demonstration cards were shown before the actual study trial.

At the conclusion of the study trial, the subjects were handed a cued-recall form that presented the 24 retrieval cues. They were asked to write as many target pairs as they could remember on the line next to the corresponding cues. No time limit was imposed for the completion of this task.

\section{Results}

The number of intralist intrusions was relatively small (each of six subjects made one erroneous pairing). Nevertheless, a strict scoring criterion was adhered to, and only target nouns properly matched with their intended retrieval cues were scored as correct.

Nouns in target pairs were considered as separate units and were scored accordingly. Mean numbers of target nouns correctly recalled in each cuing condition were converted to mean proportions, after the scores derived from one particular item that was judged to be the cause of an inflated mean in one condition were dropped from the data. Both the original data and the converted data were submitted to 2 (list) $\times 8$ (cuing condition) ANOVAs. A comparison of the results showed that only the condition in question was affected by the conversion. All results that follow, therefore, were derived from the converted data.

The finding of major interest was a significant main effect for cue condition $[F(7,266)=28.68, p<.01]$. Means and standard errors of the means for each condition are presented in Table 1.

As can be seen, our N/S treatment elicited the greatest recall, followed, in descending order, by S/IS, S/DS, $\mathrm{W} / \mathrm{S}, \mathrm{W} / \mathrm{IW}, \mathrm{W} / \mathrm{DW}, \mathrm{N} / \mathrm{W}$, and $\mathrm{S} / \mathrm{W}$ treatments. No list differences were apparent and there was no interaction of list and cuing conditions.

A Tukey (a) test for unconfounded comparisons revealed the following:

1. Recall of target pairs presented with a strong encoding cue and retrieved with a weak retrieval cue ( $\mathrm{S} / \mathrm{W}$ pairs) was statistically inferior to recall of nouns in every other condition except for recall of nouns similarly retrieved but studied without an encoding cue (our $\mathrm{N} / \mathrm{W}$ pairs). Even in the latter case, the differences between means $(\mathrm{S} / \mathrm{W}=0.079 ; \mathrm{N} / \mathrm{W}=0.231)$ closely approached significance (critical value $=0.157, \mathrm{p}=.05$ ) .

2. Retrieval evoked by strong cues was superior to retrieval evoked by weak cues in every case except one. In that case, pairs encoded with weak cues and re-

Table 1

Mean Proportions (M) of Words Recalled in Each Condition in Experiment 1

\begin{tabular}{lllllllll}
\hline & \multicolumn{8}{c}{ Cue Condition } \\
\cline { 2 - 9 } & \multicolumn{1}{c}{ N/S } & S/IS & W/S & S/DS & N/W & W/IW & S/W & W/DW \\
\hline M & 0.68 & 0.54 & 0.42 & 0.52 & 0.23 & 0.29 & 0.08 & 0.26 \\
SE & 0.043 & 0.044 & 0.043 & 0.048 & 0.048 & 0.041 & 0.025 & 0.047 \\
\hline
\end{tabular}


trieved with strong cues (W/S pairs) failed to differ statistically from pairs similarly encoded but retrieved with the same word used as an encoding cue (W/IW pairs).

3. Pairs studied in the absence of an encoding cue and retrieved with a strong cue (N/S pairs) were better recalled than pairs encoded with a weak cue and subsequently retrieved with a strong cue (W/S pairs).

4. Substituting a semantically similar noun as an encoding cue had no effect on recall. There was no significant difference between our S/IS pairs and our D/DS pairs, and no statistical difference between their counterparts, the $\mathrm{W} / \mathrm{IW}$ and $\mathrm{W} / \mathrm{DW}$ pairs.

\section{Discussion}

Most of the findings in Experiment 1 appear to support a semantic interpretation of cued recall. A major finding of this experiment was the clear superiority of strong retrieval cues over weak retrieval cues. All of the conditions in which retrieval cues closely approximated the semantic context of the encoded trace (S/IS, N/S, S/DS, and W/S conditions) were superior to all of the weak-retrieval-cue conditions, with the single exception of the W/S treatment, which failed to differ statistically from the $\mathrm{W} / \mathrm{IW}$ treatment. Even in this case, however, the difference between means was in the expected direction. These general results are comparable to those in the pilot study, in which $\mathrm{A} / \mathrm{A}, \mathrm{N} / \mathrm{A}$, and $\mathrm{I} / \mathrm{A}$ were all superior to $\mathrm{I} / \mathrm{I}$.

Although, independent of encoding treatments, there was a large effect of retrieval-cue strength, the degree of change from encoding to retrieval did not in itself produce a decrement in recall, contrary to a prediction favoring encoding specificity. Two conditions in this experiment, the S/DS and W/DW, provided proper controls for change in actual words, with semantic strength held constant. Our results showed that the S/S condition was not superior to the S/DS condition and that the $\mathrm{W} / \mathrm{W}$ condition was not superior to the W/DW condition. A second indication that change per se from encoding to retrieval did not impair recall is that recall performance in the W/IW condition was poorer than that in the S/IS condition, although in both cases retrieval cues were identical to encoding cues. Furthermore, recall in the W/IW condition was inferior to that in the S/DS and N/S conditions, although, in both of these latter cases, retrieval cues differed from encoding cues. All of these findings serve to eliminate the reinstatement of the encoding cue as a necessary condition for recall.

Because we did not replicate Tulving and Thomson's (1973) procedure exactly, there is one additional issue that merits discussion. Their experiments were designed in such a way that the subjects expected to be cued at recall with the same word that had served as the encoding cue, thus ensuring that the encoding cue would be duly attended to during encoding. Since we chose not to "set up" our subjects in a similar fashion, the argument might be raised that our "weak" encoding cues were simply ignored and therefore did not serve as functional episodic cues. There is evidence, however, that this was not the case.

Note that, in Experiment 1, inattention to the encoding cue at study would in essence render all of the strong-retrieval-cue conditions functionally equivalent. However, analysis produced a significant difference between no-cue (NS) and weak-cue (WS) conditions, suggesting a processing in which the weak cue was not ignored, but, rather, may have served to interfere with the encoding of the target pair.

The combined effect of encoding and retrieval cues on recall was rather complex in this study; however, the inclusion of the $\mathrm{S} / \mathrm{W}$ condition may provide some insight into the nature of this relationship. This condition proved to be the poorest for recall and was significantly inferior to every other conditon, including the W/IW and W/DW conditions. It may be, then, that once a strong semantic relationship has been established between two target words, this strong relationship inhibits the weaker retrieval cue's eliciting the targets. Conversely, extension of the semantic context through the presence of weak associates (as in the W/S condition) may attenuate the semantic strength of the trace, so that even retrieval with a strong cue lacks the strength necessary to facilitate retrieval over a repeated weak cue (the W/IW condition).

\section{EXPERIMENT 2}

Only a few studies have explored the relative effects of varying amounts of semantic context on verbal processes. From research in lexical access, for instance, there are reports that semantic facilitation in word identification attributed to the presence of contextual cues appears to have an additive effect (Blank \& Foss, 1978; Foss, Cirilo, \& Blank, 1979). Blank and Foss used unambiguous sentences in which the direct object in the sentence preceded a target word in a phonememonitoring task. Verbs and adjectives that preceded the direct objects were either contextually related or contextually unrelated to them. Reaction times necessary to identify targets showed not only that there was facilitation of access when either the verb or the adjective was related to the object, but also that the amount of facilitation that resulted when both a related verb and a related adjective provided semantic information was equal to the sum of facilitation provided when each cue appeared in isolation.

A study that tested word recall (Roediger \& Adelson, 1980) failed to demonstrate a similar effect. Roediger and Adelson attempted to establish a gradient for semantic strength by using, as encoding cues, associates that they judged to be strongly related to the target word (ADDRESS/TALK), weakly related (ADDRESS/ ORATION), or related to an alternate context (ADDRESS/RESIDENCE). A strong synonym of the target 
in its original interpretation (SPEECH) served as the retrieval cue. They found that more targets were recalled when encoded with weak and strong cues than when encoded with cues biasing alternate meanings, but that there was no facilitation of strong over weak encoding mates. This may have been due, however, to a lack of sensitivity in the criterion that they adopted for designating encoding cues as "strong" or "weak."

In Experiment 1, the semantic strength of the target items was held constant. Retrievability was directly related to the semantic compatibility of the encoding and retrieval cues. Experiment 2 was designed to determine whether the quantitative relationship between the semantic strength of the to-be-recalled item and that of the retrieval cue influences the ease with which a target is retrieved. We systematically varied the strength of our encoded traces by presenting noun triads in which a target noun was accompanied by a pair of strongly related coordinates, one weakly related and one strongly related coordinate, or two weakly related coordinates. The three encoding conditions were crossed with strong and weak retrieval conditions to test the independent influence of encoding versus retrieval-cue strength.

The added benefit of this procedure was that it allowed us to eliminate a nagging problem inherent in designs that couple targets with encoding cues, namely, the difficulty of differentiating between the role of the encoding cue and the role of the target. In this experiment, we were able to control for the uncertain status of the encoding cue by eliminating it entirely. We asked subjects to remember (and subsequently tested them for recall of) all three words of each triad. For the purpose of manipulation, one word of each triad was designated as the single target and was accompanied by strong and/ or weak coordinates (chosen, as in Experiment 1, by the degree of featural overlap that they shared with the targets). It was in the extent of the relationship of each of the other two coordinates around the pivotal target that the semantic strength of each triad was defined.

We expected that recall would be enhanced in those conditions in which strong semantic encoding cues were paired with strong retrieval cues. We predicted that the condition that would yield the best recall would be the one in which a strong encoding condition was cued by a strong retrieval cue. We also expected that the differential effect of strong and weak retrieval cues on recall would be greatest when the encoding condition was strong and would diminish as the encoding condition became weaker. We hypothesized that the noun-classification data would similarly reveal differences associated with strength of encoding and retrieval. First, in the case of a strong retrieval cue, we expected that the stronger the encoding condition, the greater the probability of recall of a strong item. Second, in the case of an encoding condition in which both strong and weak items were included and retrieval cues were strong, we expected that strong items would be elicited with a higher probability than would weak items.

\section{Method}

Subjects. Twenty-eight male and female students who had not participated in our previous experiment were recruited from Framingham State College. The subjects were assigned randomly to one of two study lists and were tested individually or in pairs. Each subject served in all encoding and retrieval conditions.

Materials and Procedure. The general method of establishing a stimulus pool was similar to that used in Experiment 1, with some variation in categories and additional "weak" nouns generated for each category. The words in the stimulus pool for Experiment 2 appear in Appendix B. As before, four nouns that shared a maximum featural overlap were selected from each of 24 categories. One noun from each of these groups was chosen to serve as a target word, and two were selected to become "strong" encoding mates. The fourth word was relegated to use as a "strong" retrieval cue. These assignments were random, except when constrained by the necessity of avoiding crosscuing. Similarly, for each category, three nouns that shared a minimal featural overlap with the previous four (and with each other) were generated. Two of these nouns were arbitrarily chosen to appear as "weak" encoding mates; the remaining noun was designated as a "weak" retrieval cue.

Two lists, each representing the same 24 categories, were then constructed. Target words were the same in both lists but were presented in different randomly derived conditions, with the restriction that all words cued by strong retrieval cues in List 1 were assigned to weak-retrieval-cue conditions in List 2. Strong, moderate, and weak encoding conditions were designed by matching target nouns with: (1) a pair of "strong" mates (strong encoding condition, S), (2) one "strong" mate and one "weak" mate (moderate encoding condition, M), or (3) two "weak" mates (weak encoding condition,W). Correspondingly, retrieval cues were either "strong" (strong retrieval condition, S) or "weak" (weak retrieval condition, W). Illustrated using the single category ANIMAL, the six resulting treatment conditions are presented in Table 2.

Because we were interested in the relationship between the (arbitrarily selected) target words and their various encoding mates, we asked subjects to recall all three of the words in each triplet. As can be seen in Table 2, the nouns making up our triplets appeared in one of four presentations. For the purpose of analysis, we classified them thus: (1) as a noun in a strong triplet of nouns (designated by the superscript "A"), (2) as a noun in a strong pair, accompanied by a weak noun (designated by the superscript "B"), (3) as the weak noun accompanied by a strong pair of nouns (designated by "C"), or (4) as a noun in a weak triplet of nouns (designated as "D"). The superscripts " $a$," "b," "c," and "d" indicate nouns similarly classified but cued by weak, rather than strong, retrieval cues.

The preparation of stimuli was similar to that in Experiment 1 , but with three nouns (the target word and two encoding mates), typed in lowercase letters, appearing in the center of each index card. The position of the target word within each triplet was determined randomly. The order of stimuli within

Table 2

The Six Treatment Conditions Used in Experiment 2

\begin{tabular}{|c|c|c|c|}
\hline $\begin{array}{l}\text { Encoding/ } \\
\text { Retrieval }\end{array}$ & Target & Mates & $\begin{array}{l}\text { Retrieval } \\
\text { Cue }\end{array}$ \\
\hline $\mathrm{S} / \mathrm{S}$ & jaguar ${ }^{A}$ & lion $\mathrm{A} /$ tiger $^{\mathrm{A}}$ & leopard \\
\hline $\mathrm{M} / \mathrm{S}$ & jaguar $B$ & $\operatorname{lion} B /$ sheep $C$ & leopard \\
\hline $\mathrm{W} / \mathrm{S}$ & jaguar D & rat D/sheep D & leopard \\
\hline $\mathrm{S} / \mathrm{W}$ & jaguar $^{a}$ & liona/tiger ${ }^{a}$ & poodle \\
\hline $\mathrm{M} / \mathrm{W}$ & jaguarb & lion $b /$ sheepc & poodle \\
\hline $\mathrm{W} / \mathrm{W}$ & jaguard & $\mathrm{rat} d /$ sheep $^{\mathrm{d}}$ & poodle \\
\hline
\end{tabular}

Note-See text for explanation of symbols and notation. 
lists was the same for all subjects, but was randomized within blocks of six so that one item from each treatment condition appeared in each six-stimulus block. The procedure was essentially the same as in Experiment 1. Cued-recall lists presented the 24 retrieval cues also randomized within blocks of six, guaranteeing that one cue corresponding to each cue condition appeared within each six-item block. Again, the exception was that cues appropriate to the last six stimuli seen during study were excluded from the first six retrieval cues. The subjects were told that none of the cue words had been seen previously but that each word should remind them of a particular triplet. They were asked to reproduce as many of the three words as they could remember on the line next to the corresponding cue. No time limit was set.

\section{Results}

Three separate analyses were performed on the data. The first two involved a 2 (list) $\times 3$ (encoding condition) $x 2$ (retrieval cue) mixed-design ANOVA with list as a between-subjects variable and encoding and retrieval cue conditions as within-subject factors. The first of these two measures was the proportion of target words correctly recalled, and the second was the proportion of total number of words correctly recalled for each condition. The analysis of the proportion of total words recalled was consistent with the findings for the target words. Therefore, only the findings for the target words are reported.

The mean and standard error of the mean of correctly recalled target words for each condition of list, encoding, and retrieval cue appear in Table 3 . In the analysis of proportion of target words, the main effect of list was not statistically significant. Retrieval-cue effects were present $[\mathrm{F}(1,26)=17.49, \mathrm{p}<.01$, MSe $=$ $.055]$, with stronger retrieval cues producing better recall. Encoding condition was also statistically significant $[F(2,52)=16.43, p<.05]$. A Newman-Keuls test yielded reliable differences between $S$ and $W$ encoding $(p<.01)$ and between $S$ and $M$ encoding $(p<.01)$. However, the difference between the $M$ and $W$ encoding conditions was not significant.

The list $\mathrm{x}$ retrieval cue interaction was statistically

Table 3

Mean Proportions (M) and Standard Errors (SE) of Target Words Recalled in Each Condition in Experiment 2

\begin{tabular}{|c|c|c|c|c|c|c|c|}
\hline \multirow{3}{*}{$\begin{array}{c}\text { Retrieva } \\
\text { Cue }\end{array}$} & & \multicolumn{6}{|c|}{ Encoding Condition } \\
\hline & & \multicolumn{2}{|c|}{ Strong } & \multicolumn{2}{|c|}{ Moderate } & \multicolumn{2}{|c|}{ Weak } \\
\hline & & $S / S$ & $S / W$ & $\mathrm{M} / \mathrm{S}$ & $\mathrm{M} / \mathrm{W}$ & $W / S$ & $W / W$ \\
\hline \multicolumn{8}{|c|}{ List 1} \\
\hline Strong & $\begin{array}{l}\mathrm{M} \\
\mathrm{SE}\end{array}$ & $\begin{array}{l}0.61 \\
0.073\end{array}$ & & $\begin{array}{l}0.57 \\
0.080\end{array}$ & & $\begin{array}{l}0.34 \\
0.077\end{array}$ & \\
\hline Weak & $\begin{array}{l}M \\
\text { SE }\end{array}$ & & $\begin{array}{l}0.34 \\
0.062\end{array}$ & & $\begin{array}{l}0.29 \\
0.069\end{array}$ & & $\begin{array}{l}0.18 \\
0.055\end{array}$ \\
\hline \multicolumn{8}{|c|}{ List 2} \\
\hline Strong & $\begin{array}{l}\mathrm{M} \\
\mathrm{SE}\end{array}$ & $\begin{array}{l}0.61 \\
0.062\end{array}$ & & $\begin{array}{l}0.41 \\
0.056\end{array}$ & & $\begin{array}{l}0.23 \\
0.072\end{array}$ & \\
\hline Weak & $\begin{array}{l}\text { M } \\
\text { SE }\end{array}$ & & $\begin{array}{l}0.52 \\
0.076\end{array}$ & & $\begin{array}{l}0.16 \\
0.042\end{array}$ & & $\begin{array}{l}0.38 \\
0.057\end{array}$ \\
\hline
\end{tabular}

significant $[F(1,26)=5.66, \mathrm{p}<.05, \mathrm{MSe}=.055]$. A Tukey (a) test for unconfounded means in an interaction table yielded a difference between the $S$ and $W$ retrieval cues that was statistically reliable for List 1 $(\mathrm{p}<.01)$ and differences in the same direction that approached, but did not reach, significance for List 2 . The encoding $x$ list interaction was statistically significant $[F(2,52)=4.27, p<.05, \mathrm{MSe}=.050]$. A Tukey (a) test for unconfounded means yielded a significant difference between the $S$ and $W$ encoding conditions for both lists $(\mathrm{p}<.01$ in both cases) and a nonsignificant difference between the $\mathrm{M}$ and $\mathrm{W}$ encoding conditions for both lists. However, the difference between $S$ and $M$ encoding was significant for List $2(p<.01)$ but was not statistically reliable, although it was in the same direction, for List 1.

Of primary interest was the encoding condition $\mathrm{x}$ retrieval cue interaction, which reached significance $[F(2,52)=5.14, p<.05, \mathrm{MSe}=.047]$. A NewmanKeuls test was performed to compare all means in this interaction, with alpha set at .05 . Findings revealed that our $\mathrm{S} / \mathrm{S}$ targets were better recalled than were targets in any other condition. The difference between $M / S$ and W/S was not significant. The S/W condition yielded superior recall to the $M / W$ and $W / W$ conditions, but the latter two conditions did not differ from each other.

At the .05 level of significance, the difference between the $S$ and $W$ retrieval cues in ability to elicit recall was significant for the $S$ and $M$ encoding condition but not for the $W$ encoding condition. As the encoding strength decreased from strong to weak, the ability of the strong retrieval cue relative to that of the weak retrieval cue in the elicitation of recall diminished. The list $\mathrm{x}$ encoding condition $\mathrm{x}$ retrieval cue interaction was not significant.

Our final analysis was a 2 (list) $\mathrm{x} 4$ (noun presentation) $\times 2$ (retrieval cue) ANOVA that utilized our previously defined noun classifications. Since the total numbers of recallable words varied according to classification, it was necessary to first convert scores to proportions. The results showed a main effect for retrieval cue $[F(1,26)=33.01, p<.01]$, with strong cues outperforming weak, and for noun presentation $[F(3,78)=$ $26.28, \mathrm{p}<.011$, with "A(a)" nouns (mean $=0.53$ ) superior to " $\mathrm{B}(\mathrm{b})$," "C(c)," and " $\mathrm{D}(\mathrm{d})$ " nouns (means = $0.35,0.25$, and 0.26 , respectively).

The interaction of noun presentation $\mathrm{x}$ retrieval cue $[F(3,78)=4.99, p<.01]$ was submitted to a Tukey (a) test for unconfounded means, with alpha set at .05 . "A" nouns (mean $=0.62$ ) were found to be better recalled than all other types of classifications. " $B$ " nouns (mean $=0.46$ ) were better recalled than were " $C$ " $($ mean $=0.30)$, "D" (mean $=0.27)$, and " $b$ " (mean $=0.25)$ nouns; and "a" nouns (mean $=0.44)$ were better recalled than were "b," "c" (mean $=0.21)$, and "d" $($ mean $=0.24)$ nouns.

\section{Discussion}

The major contribution of Experiment 2 was the demonstration that the strength of encoding, as defined 
by the relative number of highly related words, was directly related to recall. This was evidenced by the superior performance in the strong encoding condition relative to that in the moderate and weak encoding conditions. Unfortunately, we failed to achieve the desired consistency, since the difference between the moderate and weak encoding conditions did not achieve statistical significance. Nevertheless, this finding of an increase in the strength of encoding with an increase in the number of semantically related words is consistent with Blank and Foss's (1978) finding of an additive facilitation of reaction time when more than one contextual cue is present.

A finding central to our hypothesis was the significant encoding condition $\mathrm{x}$ retrieval cue interaction. With increase in encoding strength from weak to strong, the ability of a strong retrieval cue relative to a weak cue to elicit recall was increased. In addition, the S/S condition elicited recall that was superior to any other condition. This interaction between the semantic strength of the encoding condition and that of the retrieval cue adds weight to the argument that the strength of the semantic component during encoding and its relationship to the retrieval cue are strongly predictive of recall.

Analysis of noun-classification data provided further support for the hypothesis that the number of highly related semantic associates is directly related to the probability of recall of each associate. The strength of recall was especially effective when strong semantic associates served as retrieval cues. "A" nouns (nouns that appeared with two strong associates) had the highest probability of retrieval. " $B$ " nouns (the strong doublets in the $M$ condition) had a higher probability of recall than did either " $C$ " nouns (the single weak associate in the $M$ conditions) or " $D$ " nouns (nouns that appeared with two weak associates). There was no difference in the probability of recall of " $C$ " and " $D$ " nouns. These findings lend additional support to the hypothesis of a quantitative increment in encoding strength with an increase in the relative number of strong semantic associates. Note that " $B$ " nouns were more effectively recalled than were " $\mathrm{C}$ " nouns even though these nouns were presented within the same $M$ triad. It would thus appear that any facilitation of recall for words in the $M$ condition could only be attributed to the semantic overlap of the " $B$ " nouns.

It might be argued that a strict associationistic position could successfully account for our findings. That is, by increasing the number of strongly associated coordinates that accompanied our targets, we also increased the probability that any one of the three coordinates (target or encoding mates) might be initially evoked by a strong retrieval cue. The noun first accessed might then, in turn, serve as an additional retrieval cue for the remaining coordinates. Indeed, analysis of our nounclassification data offers no evidence that this was not the case. However, according to this view, we would expect that the probability of one encoding coordinate's "cuing" another would be constant, regardless of the strength of the retrieval cue. Consequently, although the function relating recall to encoding in the weakretrieval-cue conditions might be lower than in the strong-retrieval-cue conditions, the two functions should nevertheless be parallel.

Encoding strength was defined in this study by the extent of semantic-feature overlap. Similarly, strength of the retrieval cue was defined by its degree of overlap with the encoding coordinates. In our current proposal, the strong retrieval cue would more likely access the strong encoding coordinates than would the weak one. This differential effect on recall was expected to diminish with weaker encoding. Therefore, the obtained interaction is more consistent with the current proposal than with a strict associationistic position.

An unexpected finding in Experiment 2 was the superior recall of the $S / W$ targets in comparison with the $M / W$ targets. The $S / W$ and $M / W$ conditions in Experiment 2 are comparable to the $S / W$ and $W / D W$ conditions in Experiment 1, with the exception that in Experiment 2 the third word appearing with the target pair was designated as an "encoding cue" and not as a to-beremembered word. In Experiment 1, the $S / W$ condition was inferior to the W/DW condition; indeed, of all the conditions, it was the weakest combination for retrieval. Whether this difference in findings is somehow related to design variations remains to be explored.

\section{GENERAL DISCUSSION}

The evidence from both experiments indicates that semantic relatedness during encoding and retrieval is a strong determinant of degree of recall. Thus, the present study defined certain limits to the encoding-specificity hypothesis, which maintains that the particular word present at encoding and its unique semantic characteristics, as well as its perceptual features, are essential to the retrievability of an item. The findings of these studies suggest that when a strong semantic bias is created during encoding, the degree of semantic compatibility between encoding and retrieval becomes the single most important determinant of recall. In Experiment 1 , this was evidenced by the superior ability of a strong retrieval cue, relative to a weak one, to elicit recall. The effect of retrieval-cue strength in this experiment was general and occurred independently of the particular encoding cues used. In addition, changing the actual encoding cue, while maintaining the strength of its semantic relatedness with its target, resulted in recall that did not differ from that elicited by the original cue. On the other hand, the repetition at retrieval of a weak cue previously used at encoding failed to enhance retrieval.

The interaction of encoding and retrieval conditions in Experiment 2 further strengthened the assertion that the semantic relationship between encoding and retrieval was the single most important predictor of cued recall. Here, strong encoding cues produced better recall when 
combined with strong retrieval cues than when combined with weak retrieval cues, an effect that was not apparent when encoding cues were weak. Similarly, for the noun-classification data, the probability of recall was highest for the coordinates in the strong encoding condition cued by strong retrieval cues ("A" nouns). Furthermore, strong semantic coordinates were better recalled than weak ones in the moderate encoding condition when cued by strong retrieval cues (" $\mathrm{B}$ " nouns compared with " $\mathrm{C}$ " nouns).

Although our results show no support for earlier held views of encoding specificity, Tulving's (1982) recent theoretical sketch of the relationship between encoding and retrieval (his "synergistic ecphory" model) is not inconsistent with our own position. According to this model, "When the memory system is in the retrieval mode, appropriate information is extracted from the cue and brought into interaction with the stored episodic information through the process of ecphory. The product of a successful act of ecphory, conjunction of information from the cue and one or more memory traces, is referred to as ecphoric information" (Tulving, 1982, p. 132). In Tulving's model, this ecphoric information translates directly into recollective experience, which, in turn, is converted into memory performance.

The present study has been concerned primarily with those storage/retrieval factors that maximize this type of information. It is clear from these findings that the reinstatement of shared features does much to augment the amount of information available for a successful recollective experience.

\section{REFERENCES}

BuAnk, M. A., \& Foss, D. J. Semantic facilitation and lexical access during sentence processing. Memory \& Cognition, 1978, 6, 644-652.

Conran, C. Context effect in sentence comprehension: A study of the subjective lexicon. Memory \& Cognition, 1974, 2, 130-138.

Flexser, A. J., \& Tulving, E. Retrieval independence in recog- nition and recall. Psychological Review, 1978, 85, 153-171.

Foss, D. J., Cirilo, R. K., \& BlınK, M. A. Semantic facilitation and lexical access during sentence processing: An investigation of individual differences. Memory \& Cognition, 1979, 7, 346-353.

Light, L. L., \& CARter-Sobell, L. Effects of changed semantic context on recognition memory. Journal of Verbal Learning and Verbal Behavior, 1970, 9, 1-11.

Martin, E. Generation-recognition theory and the encoding specificity principle. Psychological Review, 1975, 82, 150-153.

Moscovitch, M., \& Craik, F. I. M. Depth of processing, retrieval cues, and uniqueness of encoding as factors in recall. Journal of Verbal Learning and Verbal Behavior, 1976, 15, 447-458.

Murphy, M. D., \& Wallace, W. P. Encoding specificity: Semantic change between storage and retrieval. Journal of Experimental Psychology, 1974, 103, 768-774.

Pellegrino, J. W., \& Salzberg, P. M. Encoding specificity in cued recall and context recognition. Journal of Experimental Psychology: Human Learning and Memory, 1975, 104, 261-270.

Reder, L. M., Anderson, J. R., \& Bjork, R. A. A semantic interpretation of encoding specificity. Journal of Experimental Psychology, 1974, 10, 648-656.

Roediger, H. L., \& Adelson, B. Semantic specificity in cued recall. Memory \& Cognition, 1980, 8, 65-74.

Santa, J. L., \& Lamwers, L. L. Encoding specificity: Fact or artifact. Journal of Verbal Learning and Verbal Behavior, 1974, $13,412-423$.

Thomson, D. M., \& Tulving, E. Associative encoding and retrieval: Weak and strong cues. Journal of Experimental Psychology, 1970, 86, 255-262.

Tulving, E. Relation between encoding specificity and levels of processing. In L. S. Cermak \& F. I. M. Craik (Eds.), Levels of processing in human memory. New York: Halsted Press, 1979.

Tulving, E. Synergistic ecphory in recall and recognition. Canadian Journal of Psychology, 1982, 36, 130-147.

Tulving, E., \& Oslen, S. Effectiveness of retrieval cues in memory for words. Journal of Experimental Psychology, 1968, 7, 593-601.

Tulving, E., \& Thomson, D. M. Encoding specificity and retrieval processes in episodic memory. Psychological Review, $1973,80,352-373$.

Warren, R. E., \& Warhen, N. T. Dual semantic encoding of homographs and homophones embedded in context. Memory \& Cognition, 1976, 4, 586-592.

Yates, J. Priming dominant and unusual senses of ambiguous words. Memory \& Cognition, 1978, 6, 636-643.

Appendix A

Stimulus Words Used in Experiment 1

\begin{tabular}{|c|c|c|c|c|c|c|}
\hline Condition & Targets & $\begin{array}{l}\text { Encoding } \\
\text { Cue }\end{array}$ & $\begin{array}{l}\text { Retrieval } \\
\text { Cue }\end{array}$ & Targets & $\begin{array}{l}\text { Encoding } \\
\text { Cue }\end{array}$ & $\begin{array}{l}\text { Retrieval } \\
\quad \text { Cue }\end{array}$ \\
\hline$N / S$ & $\begin{array}{l}\text { oven/dishwasher } \\
\text { second/hour } \\
\text { father/sister }\end{array}$ & & $\begin{array}{l}\text { refrigerator } \\
\text { minute } \\
\text { mother }\end{array}$ & $\begin{array}{l}\text { Norway/Finland } \\
\text { robin/sparrow } \\
\text { oak/maple }\end{array}$ & & $\begin{array}{l}\text { Sweden } \\
\text { bluejay } \\
\text { elm }\end{array}$ \\
\hline S/IS & $\begin{array}{l}\text { pen/crayon } \\
\text { tumbleweed/hay } \\
\text { socks/slippers }\end{array}$ & $\begin{array}{l}\text { pencil } \\
\text { sagebrush } \\
\text { shoes }\end{array}$ & $\begin{array}{l}\text { pencil } \\
\text { sagebrush } \\
\text { shoes }\end{array}$ & $\begin{array}{l}\text { snow/hail } \\
\text { satin/silk } \\
\text { teacher/architect }\end{array}$ & $\begin{array}{l}\text { blizzard } \\
\text { taffeta } \\
\text { lawyer }\end{array}$ & $\begin{array}{l}\text { blizzard } \\
\text { taffeta } \\
\text { lawyer }\end{array}$ \\
\hline $\mathrm{W} / \mathrm{S}$ & $\begin{array}{l}\text { polio/measles } \\
\text { leopard/jaguar }\end{array}$ & $\begin{array}{l}\text { gangrene } \\
\text { dinosaur }\end{array}$ & $\begin{array}{l}\text { mumps } \\
\text { tiger }\end{array}$ & $\begin{array}{l}\text { eye/nose } \\
\text { playpen/bassinet }\end{array}$ & $\begin{array}{l}\text { knee } \\
\text { table }\end{array}$ & \\
\hline S/DS & $\begin{array}{l}\text { bus/car } \\
\text { beer/rum } \\
\text { baseball/tennis } \\
\text { assault/murder }\end{array}$ & $\begin{array}{l}\text { sleigh } \\
\text { whiskey } \\
\text { football } \\
\text { robbery }\end{array}$ & $\begin{array}{l}\text { taxi } \\
\text { wine } \\
\text { basketball } \\
\text { burglary }\end{array}$ & $\begin{array}{l}\text { licorice/lollipop } \\
\text { waltz/fox-trot } \\
\text { submarine/destroyer } \\
\text { hotel/house }\end{array}$ & $\begin{array}{l}\text { bread } \\
\text { tango } \\
\text { battleship } \\
\text { apartment }\end{array}$ & $\begin{array}{l}\text { fudge } \\
\text { rhumba } \\
\text { warship } \\
\text { motel }\end{array}$ \\
\hline $\mathrm{N} / \mathrm{W}$ & $\begin{array}{l}\text { Norway/Finland } \\
\text { robin/sparrow } \\
\text { oak/maple }\end{array}$ & & $\begin{array}{l}\text { Bermuda } \\
\text { turkey } \\
\text { bamboo }\end{array}$ & $\begin{array}{l}\text { oven/dishwasher } \\
\text { second/hour } \\
\text { father/sister }\end{array}$ & & $\begin{array}{l}\text { toaster } \\
\text { semester } \\
\text { cousin }\end{array}$ \\
\hline
\end{tabular}


Appendix A (continued)

\begin{tabular}{|c|c|c|c|c|c|c|}
\hline Condition & Targets & $\begin{array}{c}\text { Encoding } \\
\text { Cue }\end{array}$ & $\begin{array}{l}\text { Retrieval } \\
\text { Cue }\end{array}$ & Targets & $\begin{array}{l}\text { Encoding } \\
\text { Cue }\end{array}$ & $\begin{array}{c}\text { Retrieval } \\
\text { Cue }\end{array}$ \\
\hline
\end{tabular}

Appendix B

Stimulus Pool for Words Used in Experiment 2

\begin{tabular}{|c|c|c|c|c|c|c|}
\hline \multirow{2}{*}{$\frac{\text { Target Word }}{\text { whiskey }}$} & \multicolumn{2}{|c|}{ Strong Encoding Mates } & \multicolumn{2}{|c|}{ Weak Encoding Mates } & \multirow{2}{*}{$\begin{array}{c}\begin{array}{c}\text { Strong Retrieval } \\
\text { Cue }\end{array} \\
\text { rum }\end{array}$} & \multirow{2}{*}{$\begin{array}{c}\begin{array}{c}\text { Weak Retrieval } \\
\text { Cue }\end{array} \\
\text { milk }\end{array}$} \\
\hline & beer & gin & tea & lemonade & & \\
\hline crib & bassinet & playpen & table & lamp & highchair & sofa \\
\hline jaguar & lion & tiger & sheep & rat & leopard & poodle \\
\hline daffodil & carnation & rose & cactus & sagebrush & daisy & fern \\
\hline licorice & jellybean & lollipop & bread & onion & fudge & bacon \\
\hline polio & measles & chickenpox & arthritis & gangrene & mumps & scurvy \\
\hline $\operatorname{taxi}$ & car & bus & sleigh & helicopter & truck & unicycle \\
\hline bluejay & sparrow & canary & penguin & turkey & robin & ostrich \\
\hline rape & robbery & assault & jaywalking & plagiarism & murder & loitering \\
\hline basketball & hockey & baseball & gymnastics & billiards & football & surfing \\
\hline tango & rhumba & fox-trot & ballet & square-dance & waltz & hula \\
\hline hotel & house & motel & igloo & wigwarn & apartment & palace \\
\hline teacher & architect & accountant & butler & gardener & lawyer & jockey \\
\hline Norway & Sweden & Denmark & India & Bermuda & Finland & Argentina \\
\hline submarine & destroyer & cruiser & canoe & ferry & battleship & sailboat \\
\hline ear & mouth & nose & abdomen & finger & eye & knee \\
\hline boot & shoe & socks & belt & nightgown & slipper & blouse \\
\hline velvet & satin & silk & denim & corduroy & taffeta & flannel \\
\hline month & year & week & semester & morning & decade & minute \\
\hline hurricane & blizzard & tornado & sunshine & shower & typhoon & fog \\
\hline maple & oak & birch & bamboo & palm & elm & sequoia \\
\hline trumpet & saxophone & trombone & ukelele & harp & bugle & harmonica \\
\hline $\begin{array}{l}\text { bedroom } \\
\text { encyclopedia }\end{array}$ & $\begin{array}{l}\text { kitchen } \\
\text { thesaurus }\end{array}$ & $\begin{array}{l}\text { den } \\
\text { atlas }\end{array}$ & $\begin{array}{l}\text { theater } \\
\text { magazine }\end{array}$ & $\begin{array}{l}\text { auditorium } \\
\text { diary }\end{array}$ & $\begin{array}{l}\text { bathroom } \\
\text { dictionary }\end{array}$ & $\begin{array}{l}\text { laboratory } \\
\text { novel }\end{array}$ \\
\hline
\end{tabular}

(Manuscript received November 8, 1982;

revision accepted for publication August 10, 1983.) 